\title{
Multiple Sclerosis in Pregnancy-A Practical Guide for the Obstetrician
}

\author{
Papa Essilfie \\ Wrightington, Wigan and Leigh Teaching Hospitals, Wigan, UK \\ Email: papaessilfie@doctors.org.uk
}

How to cite this paper: Essilfie, P. (2020) Multiple Sclerosis in Pregnancy-A Practical Guide for the Obstetrician. Open Journal of Obstetrics and Gynecology, 10, 1307-1314.

https://doi.org/10.4236/ojog.2020.1090120

Received: May 3, 2020

Accepted: September 21, 2020

Published: September 24, 2020

Copyright (c) 2020 by author(s) and Scientific Research Publishing Inc. This work is licensed under the Creative Commons Attribution International License (CC BY 4.0).

http://creativecommons.org/licenses/by/4.0/

\section{(c) (i) Open Access}

\begin{abstract}
Technological advances, a deeper understanding of disease processes and increased sophistication of therapeutic methods have all led to better outcomes in rare diseases which previously had devastating effects on many women's lives. The inevitable result of this progress is that women, who in the past did not contemplate pregnancy because of significant morbidity, now get to adulthood and are reasonably "disease free" enough to have their own families. The ever expanding, but relatively new specialty of Obstetric medicine seeks to further improve the outcome in pregnant women with intercurrent disease by enhancing the literature base, thereby contributing to the creation of appropriate guidance in the management of these patients. This article is a brief but useful guide for the busy obstetrician who may have limited experience in dealing with multiple sclerosis in pregnant women.
\end{abstract}

\section{Keywords}

Inflammatory Plaques, Neurodegeneration, Demyelination, Diplopia, Fetal Growth Restriction, Immunomodulating Therapy, Lactational Amenorrhea, Small for Gestational Age (SGA)

\section{Introduction}

Multiple sclerosis (MS) is the commonest acquired neurological disorder in the northern hemisphere. In the United Kingdom and many other European countries it is also the commonest cause of disability in the young. The incidence of the condition in women is at least 2 times that in men. The condition tends to affect women in their childbearing years thus making an encounter between the obstetrician and the patient with MS a common one. Prevalence rates in England vary between 80 and 287 per 10,000 with higher rates in Northern Scotland and Orkney [1]. Many obstetricians have limited knowledge on MS. This text is a 
practical, concise guide for the Obstetrician.

\section{Pathogenesis}

Multiple sclerosis is an autoimmune, chronic inflammatory disorder of the Central Nervous system. It is characterized by the infiltration of the central nervous system by autoreactive, simplified lymphocytes. This initially results in the formation of inflammatory plaques on the brain and spinal cord with subsequent demyelination and neurodegeneration [2]. The clinical manifestation of this process is a gradual accumulation of neurologic deficits. Both genetic and environmental factors are important in the aetiology of the condition. Although the exact mechanism of inheritance is unknown there is a well-documented increased concordance rate in monozygotic twins. Children who have both parents affected have a much higher incidence of the condition when compared to the background population. Important environmental factors in the acquisition of MS include Obesity, smoking and infection with the EB (Epstein Barr) virus.

\section{Clinical Features}

Clinical features are varied and depend on the part of the Central nervous system (CNS) affected. Signs and symptoms may include visual defects (e.g. diplopia or optic neuritis), motor symptoms (lack of coordination, tremor), sensory symptoms (numbness, a tingling sensation in any or all four extremities), urinary incontinence or cognitive impairment. Diagnosis is complex and is usually made by a certified neurologist. It often employs the use of symptoms, physical signs, radiological imaging and serum investigations. 4 distinct patterns of disease are described.

1) Relapsing Remitting MS (RRMS): This pattern is characterized by a series of relapses and remissions (complete or partial) over a period of many years or even decades. $85 \%$ of patients initially follow an RRMS course [3].

2) Secondary Progressive MS (SPMS): In this pattern remissions become less distinct and there is progressive disability. Over a period many patients with RRMS will evolve into the SPMS pattern.

3) Primary Progressive MS (PPMS): This is characterized by a progressive course from the onset. There is NO RRMS phase.

4) Progressive Relapsing MS (PRMS): This is characterized by a progressive course from the beginning but also with episodes of relapses from which there is often no full recovery.

\section{Investigations}

Most MS patients who attend the antenatal clinic will already have a known diagnosis making antenatal investigations unnecessary. Occasionally an MRI scan would be needed to assess disease activity in pregnancy. MRI scans are generally safe in pregnancy as they do not rely on the use of ionising radiation. An MRI scan does not expose the fetus to radiation. Gadolinium contrast enhanced MRI 
scans are however contra-indicated. Gadolinium may cross the placenta in the $2^{\text {nd }}$ and $3^{\text {rd }}$ trimester where it is excreted by the fetal kidneys into the amniotic fluid and then re-circulated. Potentially it could cause nephrogenic systemic fibrosis in the child [4]. Below are some MRI scans of characteristic MS lesions (Figure 1 \& Figure 2).

\section{EFFECT OF PREGNANCY ON MULTIPLE SCLEROSIS}

In the past there was great anxiety associated with pregnancy in patients with MS. Many decades ago, women with MS were discouraged from falling pregnant and indeed some MS patients were advised to have a termination of pregnancy

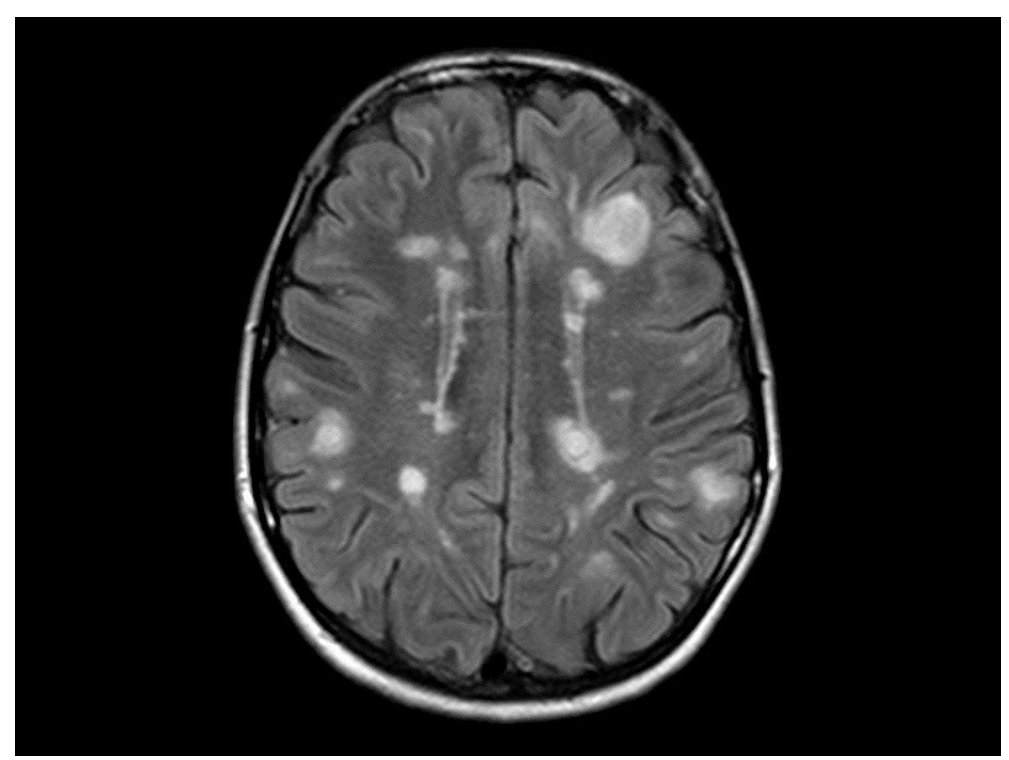

Figure 1. MRI scan of the brain in a patient with multiple sclerosis showing typical lesions.

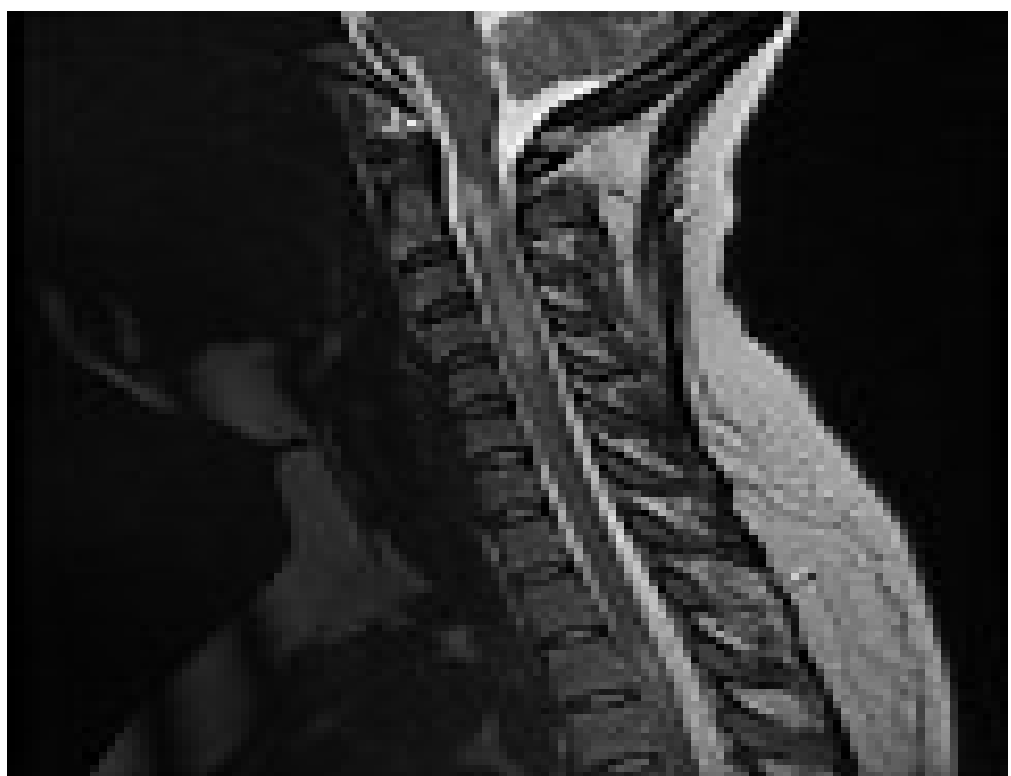

Figure 2. MRI scan of cervical spine of a patient with multiple sclerosis showing typical lesions. 
because of the disease. Greater understanding of the disease and the immunological changes in pregnancy has completely changed the advice currently given to MS patients.

Research has now shown that women with MS have fewer relapses during pregnancy. The frequency of relapse is slightly lower in the $1^{\text {st }}$ and $2^{\text {nd }}$ trimesters when compared to the pre-pregnant state. In the $3^{\text {rd }}$ trimester the frequency of relapse may fall by as much as $70 \%$ [3]. Post-partum, the relapse rate, increases substantially and the frequency of relapse may be much higher than that before pregnancy. Some $20 \%-30 \%$ of patients may have a relapse in the first $3-4$ months following delivery [5]. The single best predictor for post-partum relapse is the pre-pregnancy relapse rate. This is one of the reasons why it is essential for a woman to have well controlled disease before embarking on pregnancy.

Several reasons may account for the reduction in the frequency of relapses in MS patients during pregnancy.

1) Pregnancy is associated with a down regulation of the cellular immune response and a shift from cell mediated to humoral immunity. This shift is thought to be part of the human mechanism for preventing maternal fetal rejection in pregnancy. Patients with MS (which is a cell-mediated autoimmune disease) benefit from this shift which contributes to decreased disease activity [3].

2) The fetoplacental unit produces Interleukin 10 (IL-10) during pregnancy. IL-10 causes immune suppression in pregnancy and this may partly explain the spontaneous remission of MS during pregnancy [6].

3) There is an increased production of progesterone and oestrogen particularly in the third trimester. Both hormones are thought to possess some neuroprotective properties [3]. Physiologically, the increase in relapse rate post-partum is not unexpected given the sudden substantial decrease in the serum level of both hormones.

It is also worth noting that several studies have found no adverse effect of pregnancy on the long-term progression and disability risk of MS. Indeed, many studies have shown a beneficial effect on both. Verdu et al. in their study report that, time to wheelchair use was increased by $50 \%$ in women who developed MS before pregnancy when compared with a similar cohort of women who had no pregnancies after their diagnosis.

\section{Effect of Multiple Sclerosis on Pregnancy}

There is no evidence to suggest a major increase in adverse pregnancy outcomes in MS patients. There is no increase in the frequency of miscarriages, stillbirths, congenital abnormalities or birth defects in patients with Multiple Sclerosis.

The risk of Prematurity, low birth weight and Intra-uterine fetal growth restriction (FGR) are however slightly increased in MS patients. A systematic review by Finkelsztein et al. [7] showed a higher prevalence of prematurity and low birth weight in children born to women with MS. Preterm delivery seems to be commoner among women who are symptomatic during pregnancy when 
compared with asymptomatic MS patients.

\section{Disease Modifying Drugs}

Disease modifying drugs (DMD), also known as immunomodulating therapy is effective in treatment of MS. DMD's reduce the frequency and severity of relapses in MS patients. They also reduce the disease load found on MRI scans. Several drugs are now available for the treatment of MS. The use of any medication in pregnancy obviously has great implications. Below are some of the common agents used together with some important considerations in pregnancy (Table 1).

\section{Management}

\subsection{Antenatal}

Early booking is important to enable the formulation of management plans for the entire pregnancy. It is helpful if the patient falls pregnant at a time of disease quiescence as this improves the outcome of the pregnancy. Because prenatal clinics generally do not exist in the United Kingdom, management of the disease and the control of symptoms pre-pregnancy will largely be the responsibility of

Table 1. Table of disease modifying drugs (DMD's) used in multiple sclerosis and important considerations in pregnancy/the immediate post-partum period.

\begin{tabular}{|c|c|c|c|}
\hline DRUG & PREGNANCY CONSIDERATIONS & USE & $\begin{array}{l}\text { POST-NATAL/BREAST } \\
\text { FEEDING }\end{array}$ \\
\hline Inteferon- $\beta$ & $\begin{array}{l}\text { Only limited data exist on the drug's effect on the fetus. } \\
\text { No increased incidence of miscarriages, Congenital } \\
\text { malformation, or SGA (Small for gestational age) }\end{array}$ & $\begin{array}{l}\text { Use is contra-indicated in } \\
\text { pregnancy (Patients are usually } \\
\text { advised to stop use after } \\
\text { conception) }\end{array}$ & $\begin{array}{l}\text { Use not advised with breast } \\
\text { feeding }\end{array}$ \\
\hline Glatiramer Acetate & $\begin{array}{l}\text { Limited data. No evidence of increased frequency of } \\
\text { miscarriages, congenital malformations, or SGA }\end{array}$ & $\begin{array}{l}\text { Use contraindicated in } \\
\text { pregnancy (Patients are usually } \\
\text { advised to stop use after } \\
\text { conception) }\end{array}$ & $\begin{array}{l}\text { May use with caution during } \\
\text { breast feeding }\end{array}$ \\
\hline $\begin{array}{l}\text { Corticosteroids } \\
\text { (Prednisone, } \\
\text { Prednisolone) }\end{array}$ & $\begin{array}{l}\text { First trimester use has been associated with fetal } \\
\text { orofacial clefts. } \\
\text { May cause Gestational diabetes, Hypertension. } \\
\text { Heavy doses over a long period may cause FGR } \\
\text { (Intrauterine fetal growth restriction)/SGA }\end{array}$ & $\begin{array}{l}\text { Use with appropriate } \\
\text { surveillance }\end{array}$ & $\begin{array}{l}\text { May use during breast feeding. } \\
\text { Breast feeding advised } 4 \text { hours } \\
\text { post administration to reduce } \\
\text { infant exposure. }\end{array}$ \\
\hline Natalizumab & $\begin{array}{l}\text { Limited data. } \\
\text { Not known to increase the incidence of miscarriages, or } \\
\text { congenital malformation. } \\
\text { Crosses placenta (particularly in the } 3^{\text {rd }} \text { trimester), has } \\
\text { been associated with SGA and fetal haematological } \\
\text { abnormalities (anaemia, thrombocytopenia) }\end{array}$ & $\begin{array}{l}\text { May be used as a } 2^{\text {nd }} \text { line agent in } \\
\text { challenging cases with } \\
\text { appropriate surveillance }\end{array}$ & $\begin{array}{l}\text { Use not advised with breast } \\
\text { feeding }\end{array}$ \\
\hline $\begin{array}{l}\text { Immunosuppressive } \\
\text { Agents-Methotrexate } \\
\text { Cyclophosphamide } \\
\text { Myclofentolate } \\
\text { Mitoxantrone }\end{array}$ & $\begin{array}{l}\text { Teratogenic. } \\
\text { Stop usage at least } 6 \text { months before pregnancy. } \\
\text { Ensure appropriate contraception during usage }\end{array}$ & Contra-indicated & Contra-indicated \\
\hline
\end{tabular}


the patient's GP (General Practitioner) and Neurologist.

Antenatal management should be multidisciplinary with a team including a neurologist, an obstetrician with an interest in medical disorders, an obstetric anaesthetist, a neonatologist, midwives and neurology specialist nurses.

An early dating scan and the usual antenatal booking blood tests are mandatory. At the booking appointment a full history should be taken. Medications should be reviewed, and any contra-indicated medications stopped immediately. The obstetrician must also take the opportunity to establish links between himself/herself and other members of the team through correspondence which can be documented on the patient's records. An anaesthetic review may be needed to rule out the presence of spinal cord disease which could potentially interfere with regional anaesthetic techniques. Where a patient is on a medication which requires neonatal surveillance (e.g. Natalizumab which can cause neonatal anaemia and thrombocytopenia) appropriate antenatal referrals to the neonatologist must be made.

Thromboprophylaxis should be discussed. Whilst TED (Thromboembolic deterrent) stockings for long journeys may suffice in mobile generally fit patients, low molecular weight heparin thromboprophylaxis should be considered for the wheelchair-bound patient (or those whose VTE risk is increased by concurrent morbidity).

Regular reviews by the neurologist are important to maintain vigilance in the detection of relapses. Occasionally short courses of amitriptyline may be needed to treat neurogenic pain. Patients with worsening neurogenic bladder symptoms may require frequent urinalysis to rule out urinary tract infections (which are commoner in pregnancy).

The usual mid-trimester fetal anatomical surveillance scan (FAS scan) should be performed. Where there is an active disease with frequent relapses or where medications have been required to keep the patient symptom free, Obstetric growth scans are important to detect any fetal growth restriction which may be present.

Induction of labour and caesarean section should be restricted to Obstetric indications. Well controlled MS is not an indication for either.

\subsection{Intrapartum Care}

Vaginal delivery is safe in patients with MS. Occasionally the presence of severe neurological disability may make planned elective caesarean section more practical. For patients who attempt a vaginal delivery, the incidence of emergency caesarean section does not appear to be higher than that in healthy non -affected women.

Analgesia in labour should be discussed with the patient. MS "per se" does not make the use of Epidural analgesia contraindicated. Entonox (Nitrous oxide) and opiate analgesia can also be used.

Maternal exhaustion at the end of the $2^{\text {nd }}$ stage of labour may lead to a slightly 
higher incidence of assisted vaginal delivery [8].

\subsection{Post Partum Care}

The postpartum period can be a difficult time for MS patients as relapses occur more frequently at this time because of the sudden loss of the physiological protection that pregnancy gives. Management of the post-natal period should be planned in the antenatal period. Exclusive breast feeding results in a reduction in the pulsed secretion of GNRH (Gonadotrophin releasing hormone) and LH (Luteinizing hormone). The consequent hyperprolactinemia produces anovulation and lactational amenorrhea. This hormonal "milieu" causes a reduction in the proliferation of CD4 cells ( $\alpha$-TNF producing cells) resulting in a reduction in the relapse rate of MS. The immunological effect of exclusive breast feeding can reduce the relapse rate of MS by four-fold [8]. Where there are no contra-indications, breast feeding should be encouraged.

The use of certain DMD's (e.g. Natalizumab) during the post-natal period precludes breast feeding as these agents may pass into the breast milk thus making breastfeeding contraindicated. Each patient should be treated on a "case by case" basis with the risk of postpartum relapse during lactation weighed critically against starting or continuing treatment with a DMD soon after delivery.

In patients in whom mobility is impaired, consideration should be given to maintaining thromboprophylaxis during the first 6 weeks following delivery.

Contraception must be discussed after delivery. Both oestrogen and progesterone based oral contraceptive agents are well tolerated by MS patients and may even be beneficial to the disease process. It is important to note that an increased risk of DVT (Deep vein thrombosis) has been associated with the use of the combined Oral contraceptive pill in patients with reduced mobility or increased spasticity and this must be factored into the overall risk assessment of the patient.

Long acting reversible contraceptives (e.g., IUCD's, Progesterone implants e.g. Implanon) provide long term contraception and have the added advantage of not interfering with any oral DMD's that may have to be administered in the post-natal period.

Before the patient is discharged, follow up plans/MS contact team numbers etc. should be discussed and documented in the appropriate notes.

Multiple sclerosis can be a debilitating disease but with appropriate, careful, multidisciplinary care, most women should have a favourable outcome if they chose to embark on a pregnancy.

\section{Conflicts of Interest}

The author declares no conflicts of interest regarding the publication of this paper.

\section{References}

[1] Lorenzi, A.R. and Ford, H.L. (2002) Multiple Sclerosis and Pregnancy. Postgraduate 
Medical Journal: London, 78, 460. https://doi.org/10.1136/pmj.78.922.460

[2] Boristow, N., Paul, F. and Dorr, J. (2014) Optimal Management of Multiple Sclerosis during Pregnancy: Current Perspectives. Degenerative Neurological and Neuromuscular Disease, 4, 111-120. https://doi.org/10.2147/DNND.S48618

[3] Alwan, S. and Dessa Sadovnick, A. (2012) Multiple Sclerosis and Pregnancy: Maternal Considerations. Women's Health, 8, 399-414.

https://doi.org/10.2217/WHE.12.33

[4] Webb, J.A.W., Thomsen, H.S., Morcos, S.K., Almen, T., Aspelin, P., Bellin, M.F., et al. (2005) The Use of Iodinated and Gadolinium Contrast Media during Pregnancy and Lactation. European Radiology, 15, 1234-1240.

https://doi.org/10.1007/s00330-004-2583-y

[5] Hellweig, K., Haghika, A., Rockhoff, M. and Gold, R. (2012) Multiple Sclerosis and preganacy Experience from a Nationwide database in Germany. Therapeutic Advances in Neurological Disorders, 5, 247-253.

https://doi.org/10.1177/1756285612453192

[6] Wegmann, T.G., Lin, H., Guilbert, L. and Mosmann, T.R. (1993) Bidirectional cytokine Interactions in the Maternal-Fetal Relationships: Is Successful Pregnancy a TH2 Phenomenon? Immunology Today, 14, 353-356.

https://doi.org/10.1016/0167-5699(93)90235-D

[7] Finkelsztejn, A., Brooks, J.B., Paschoal, F.M. and Fragoso, Y.D. (2011) What Can We Really Tell Women with Multiple Sclerosis? A Systematic Review and Meta-Analysis of the Literature. BJOG, 118, 790-797. https://doi.org/10.1111/j.1471-0528.2011.02931.x

[8] Kanagaraj, P., Evangelou, N. and Kapoor, D. (2019) Multiple Sclerosis and Pregnancy. The Obstetrician \& Gynaecologist, 211, 177-184.

https://doi.org/10.1111/tog.12576 